\title{
CONTRIBUIÇÕES DA INFORMÁTICA PARA A INCLUSÃO SOCIAL DA PESSOA IDOSA
}

\author{
José Ramon Nunes Ferreira, Hospital Universitário Júlio Bandeira/HUJB/UFCG \\ joseramonnunes@gmail.com \\ Eliane de Sousa Leite, Unidade Acadêmica de Enfermagem/UAENF/UFCG \\ elianeleitesousa@yahoo.com.br
}

Carlos Davidson Pinheiro, Unidade Acadêmica de Ciências Exatas-Natureza/UACEN/UFCG

cdpinheiro@gmail.com

PALAVRAS-CHAVE: Inclusão social; Idoso; Informática.

\section{INTRODUÇÃO}

Nos últimos anos, tem-se vivenciado período de grandes revoluções e transformações cujo impacto na vida das pessoas é muito significativo. Junto a essas transformações, vê-se a proliferação das tecnologias de comunicação e de informação. Esse fato tem despertado um grande interesse entre os idosos quanto ao aprendizado da informática, considerando os benefícios que ela pode oferecer às suas vidas (KREIS et al., 2010).

A tecnologia da informação surge, então, como instrumento contributivo para redução do isolamento, estimulação mental e, finalmente, bem-estar da pessoa idosa, podendo também facilitar ou promover o processo de comunicação com a família ou amigos, fomentando, desta maneira, as relações interpessoais ou mesmo promovendo encontros geracionais na web (KACHAR, 2010).

De acordo com Zeni et al. (2013), ao usar a informática os idosos têm a possibilidade de explorar os próprios interesses, de manter a autonomia, de exercer a cidadania, de localizar outros mundos, de cruzar fronteiras geográficas, de estabelecer contatos com outras gerações, além da família e dos amigos, estimulando a mente, descobrindo e ampliando conhecimentos. Diante do exposto, o presente estudo objetivou identificar o conhecimento produzido na literatura científica acerca das contribuições da informática para a inclusão social do idoso. 


\section{METODOLOGIA}

O método adotado foi a revisão integrativa da literatura. É um dos métodos de pesquisa utilizados na Prática Baseada em Evidências (PBE) que permite a incorporação das evidências na prática clínica (BROOME, 2006). Para elaboração desta revisão integrativa foram percorridas todas as fases recomendadas: primeira fase - elaboração da pergunta norteadora; segunda fase - busca ou amostragem na literatura; terceira fase - coleta de dados; quarta fase - análise crítica dos estudos incluídos; quinta etapa - discussão e interpretação dos resultados e sexta - apresentação da revisão integrativa (MENDES; SILVEIRA; GALVÃO, 2008). A pergunta norteadora para a elaboração da revisão integrativa foi: quais as contribuições da informática para a inclusão social da pessoa idosa?

O levantamento do corpus literário a ser analisado foi obtido nas bases de dados Literatura Latino-Americana e do Caribe em Ciências da Saúde (LILACS), Medical Scientific Eletronic Library Online (SCIELO) e Base de dados de Enfermagem (BDENF). A busca foi realizada em maio de 2017. Utilizando-se os descritores: "informática", "inclusão social" e “idoso". Após leitura minuciosa dos artigos, os mesmos foram avaliados na íntegra e obtiveram-se dez artigos para compor a amostra do estudo.

\section{DESCRIÇÕES, RESULTADOS, INTERPRETAÇÕES}

\subsection{Caracterização dos artigos analisados}

Tabela 1 - Distribuição cronológica dos artigos, segundo bases de dados. Cajazeiras,PB, 2017.

\begin{tabular}{lcccccccccccc}
\hline \multicolumn{10}{c}{ Número de artigos publicados por ano } \\
Base de & 2007 & 2008 & 2009 & 2010 & 2011 & 2012 & 2013 & 2014 & 2015 & 2016 & Total \\
\cline { 2 - 12 } dados & $\mathrm{n}^{\mathbf{o}}$ & $\mathrm{n}^{\mathbf{o}}$ & $\mathrm{n}^{\mathbf{o}}$ & $\mathrm{n}^{\mathbf{o}}$ & $\mathrm{n}^{\mathbf{o}}$ & $\mathrm{n}^{\mathbf{o}}$ & $\mathrm{n}^{\mathbf{o}}$ & $\mathrm{n}^{\mathbf{o}}$ & $\mathrm{n}^{\mathbf{o}}$ & $\mathrm{n}^{\mathbf{o}}$ & $\mathrm{n}^{\mathbf{o}}$ \\
\hline SCIELO & 01 & - & - & 02 & - & 01 & - & - & - & 01 & - \\
BDENF & - & - & - & - & - & - & - & 01 & - & 01 & - \\
LILACS & 01 & - & - & - & - & - & - & 01 & 01 & - & - \\
\hline Total & $\mathbf{0 2}$ & $\mathbf{0 0}$ & $\mathbf{0 0}$ & $\mathbf{0 2}$ & $\mathbf{0 0}$ & $\mathbf{0 1}$ & $\mathbf{0 0}$ & $\mathbf{0 2}$ & $\mathbf{0 1}$ & $\mathbf{0 2}$ & $\mathbf{1 0}$ \\
\hline
\end{tabular}

Fonte: Scielo, BDENF, Lilacs, 2007-2016.

Quanto aos anos de publicação dos periódicos, observa-se que uma quantidade irrisória de trabalhos foi realizada em uma década, diante dessa escassez de publicação percebe-se que a temática informática para o idoso na perspectiva de inclusão social é um 
tema ainda pouco abordado no meio científico. Os dez artigos selecionados para esta revisão integrativa foram todos publicados em periódicos brasileiros em variadas regiões, dentre os quais podem ser citados: Revista Gaúcha Enfermagem; Revista Kairós, Revista novas Tecnologia na Educação; Computer on the Beach; Revista nova Tecnologia na Educação; Revista Educação Temática Digital; Revista Científica Interdisciplinar; Revista Intellectus e Revista Renole.

Após a leitura minuciosa dos artigos selecionados, a síntese da evidência dos estudos propõe-se estruturar quatro categorias sobre a inclusão digital do idoso, quais sejam: Motivação dos idosos para aprender informática; Dificuldades apontadas pelo idoso para uso da informática; Estratégias de Ensino-aprendizagem sobre a informática para o idoso e o Idoso e sua inserção nas Redes Sociais.

\section{Motivação dos Idosos para Aprender Informática}

Os autores Fernandes e Ferreira (2012) realizaram um estudo para averiguar as condições que ocorre a inclusão digital da terceira idade no município de Belém/PA. Como resultado mais frequente os idosos relataram que a maior motivação para aprender a informática era poder se comunicar de forma mais rápida e barata com familiares, principalmente filhos e amigos que moram distante.

Outra motivação elencada pelos idosos é a perspectiva de voltar ao mercado de trabalho ou melhorar sua atuação profissional também é apontada pelos idosos como motivos para querer se inserir digitalmente, boa parte dos indivíduos estudados mencionaram que buscam na inserção digital capacitação para voltarem ao mercado, seja para complementar a renda ou para se manter ocupado (FERNANDES; FERREIRA, 2012).

Estudos realizados por Tarallo e Sé (2016), demonstraram também que os idosos buscavam a informática para ter mais conhecimento e se informar sobre a atualidade; para utilizar o computador de forma autônoma e independente; para se socializar com familiares e amigos; aprimorar o conhecimento sobre informática; por curiosidade; para saber utilizar somente a internet; por gostar de tecnologia; necessidade para o trabalho e para fazer novos amigos. 


\section{Dificuldades apontadas pelo idoso para uso da informática}

Dentre as dificuldades relatadas pelos idosos, os problemas visuais são os mais citados e decorrem do processo de envelhecimento, que é a diminuição da acuidade visual, dificultando a aprendizagem dos idosos. Outra dificuldade também evocada foi a baixa escolaridade. Observando a prevalência de idosos com ensino médio incompleto, pesquisa demonstra que quanto mais velha é a população, mais baixo é o nível de escolaridade, pois estas pessoas tiveram menos chance de acesso a escola (KREIS, 2010). No que se refere às dificuldades no aprendizado da internet, a navegação em si e as opções dos favoritos foram as mais frequentes, seguidas de fazer pesquisas e downloads, acessar os e-mails e tarefas específicas também foi assinalado (TARALLO; SÉ, 2016).

Segundo Lamarca et al. (2015) revelaram que principais problemas no uso das tecnologias de informação e comunicação para os mais idosos a digitação, a impressão de documentos, o manuseio do mouse, o uso da internet, o acesso ao e-mail, a comunicação e baixar arquivos; bem como dificuldades quanto à acessibilidade e relacionadas ao foro cognitivo, de falta de concentração, atenção, memória.

\section{Estratégias de Ensino-aprendizagem para o ensino da informática para o idoso}

De acordo com Soares e Intoe (2015), é importante que o idoso seja introduzido no mundo da informática com abordagens e metodologias adequadas às suas necessidades, uma vez que este "novo instrumento" gera maneiras diferenciadas de relações sociais, familiares e desenvolve formas de aprendizagem que atingem a todas as idades, aproximando automaticamente gerações, além de promover ruptura com a ideia de que o idoso não aprende ou que não é produtivo.

Wasserman (2012) descreve diversas estratégias existentes para o ensinoaprendizagem e destaca que os procedimentos adotados são escolhidos pela pessoa com o intuito de facilitar a própria aquisição, armazenamento e utilização da informação e ou tarefa. A aprendizagem do uso das tecnologias também é individualizada, dependendo de cada participante, fazendo com que cada um seja o protagonista de sua própria construção de conhecimento e aprenda em seu ritmo, em uma contínua transformação, tanto de si como da sociedade em que se desenvolve.

\section{O Idoso e sua inserção nas Redes Sociais}


Os idosos estão cada vez mais utilizando as tecnologias, incluindo as redes sociais. Para este tipo de público, as redes sociais estão se tornando um local não apenas como forma de passatempo, mas como fonte de novos conhecimentos, comunicação e interações. Portanto, a partir dos textos coletados e avaliados, observa-se que a rede social mais usada é o Facebook, por ser intuitivo e se tratar de um espaço de fácil utilização para os idosos. Entre as ferramentas citadas e as mais utilizadas estão as de mensagens instantâneas, whatsapp seguidos do compartilhamento de fotos e mensagens. O que significa uma preocupação em estar mais perto de amigos e familiares, além do compartilhamento de informações com estes (DANTAS, 2010).

\section{CONSIDERAÇÕES FINAIS}

Diante da análise dos artigos pode-se afirmar que a inclusão digital na terceira idade reflete na melhoria da qualidade de vida, pois os idosos interligados ao mundo, se comunicando, através da internet, com amigos e familiares, obtendo a informação em tempo real e descobrindo que ainda é capaz de aprender, faz com que o idoso se fortaleça na sociedade contemporânea, e perceba que o envelhecer não é uma fase triste da vida e sim uma fase onde o indivíduo mantém sua capacidade de aprender e adaptar-se as novas situações do mundo moderno, tornando-o independente e autônomo.

Portanto, a inclusão digital também significa autoconhecimento e possibilidade de mudança da condição dos idosos na sociedade. Um grande desafio é tornar a vida na terceira idade plena e digna em todos os seus aspectos, e nesse sentido a inclusão digital, com aprendizado bem conduzido, é uma ferramenta bastante útil.

\section{REFERÊNCIAS}

BROOME, M. E. Integrative literature reviews for the development of concepts. In: Rodgers BL, Castro AA. Revisão sistemática e meta-análise. 2006. Disponível em: http://www.researchgate.net/publication/238248432

DANTAS, M.R.N.D. Os benefícios da inclusão digital na terceira idade - relato de experiência. Anais do Congresso Internacional de Educação Inclusiva. Florianópolis: Universidade de Santa Catarina, 2010.

FERNANDES, F.S.; FERREIRA, B. J. Inclusão Digital de Idosos: Um estudo sobre a Realidade do Município de Belém (PA). Revista Renole Novas tecnologia na Educação. v, 10, n.1, 2012. 
KACHAR, V. Terceira Idade \& Informática: Aprender revelando potencialidades. São Paulo: Cortez, 2010.

KREIS, R. A. O impacto da informática na vida do idoso. Revista Kairós. v.10, n. 2, p.15368. 2010.

LAMARCA, D. S. F et al. TIC presente nas universidades: uma análise no projeto de extensão Universidade Aberta à Terceira Idade (UNATI). $8^{\circ}$ Congresso de Extensão Universitária da UNESP, 2015.

PAULO, C. A.; TIJIBOY, A.V. Inclusão digital de pessoas da Terceira idade através da educação a distância. Revista Renole.v.3, n.1. 2007.

SOARES, M.R.P.; ISTOE, R.S.C. Alfabetização e inclusão de pessoas idosas: uma proposta interdisciplinar mediada pelas tecnologias da informação e da comunicação. Revista

Científica Interdisciplinar. v, 2, n. 17, Julho/Setembro 2015.

TARALLO, R. S.; SÉ, E. V. G. Faculdade de Jaguariúna e Faculdade Max Planck Letramento digital no ensino de informática para idosos. Revista Intellectus. v. 4, n.36, 2016.

WASSERMAN, C et al. Redes sociais: um novo mundo para os idosos. Revista Renole, Novas Tecnologias na Educação. v. 10, nº. 1, julho, 2012. 